\title{
LabView-based Modeling and Evaluation of Solar Photovoltaic Cells Energetic Efficiency
}

\author{
Szász Csaba \\ Department of Electrical Machines and Drives \\ Technical University of Cluj \\ Csaba.Szasz@emd.utcluj.ro
}

\author{
Páli Kis Dávid \\ Department of Electrical Machines and Drives \\ Technical University of Cluj
}

\begin{abstract}
As it is well known, an accurate knowledge of solar photovoltaic (PV) cell parameters from experimental data is of major importance for estimate their performances and to implement high energetic efficiency PV plants. In the last decade several solar cell models, respectively a high amount of software toolkits have been developed to evaluate their electrical behavior and performances. This paper is focused to introduce a LabView graphical programming language based solution to conveniently modeling, simulate, and evaluate solar PV cells energetic efficiency. By using their well known electrical equivalent circuits a fast and accurate PV simulator has been designed and implemented for research and energetic efficiency studies. The simulation models used has been validated through comparison of the obtained characteristics with the ones given by the manufacturers of $P V$ panels. The computer-aided simulation results carried out are in a good agreement with the manufacturer's catalogue data and the LabView-based program can serve as a very useful toolkit for engineers or researchers who require an accurate $P V$ simulator and evaluate the performances of any photovoltaic module.
\end{abstract}

Keywords- photovoltaic cell, energetic efficiency, LabView simulation, virtual instrument, solar energy;

\section{INTRODUCTION}

It is no doubt that the exhaustion and high costs of traditional fossil energy resources (oil, coal, gas and others) constrains scientists to intensified efforts for searching of alternative and non-polluting abundant energy resources. In this endeavor solar energy, as a theoretically inexhaustible renewable energy resource, and its conversion processes plays a major importance. For this reason, the continuously improvement trend of solar energy utilization-linked technologies is a leading and major importance task for engineers and researches involved in this scientific domain.

However, nowadays the vast majority of solar energy resources are obtained by using photovoltaic systems that converts the solar light energy in electrical current. It is well known that PV systems behave in an extraordinary and useful way: produce no pollution while producing electricity, can operate at moderate temperatures, consume no fuel to operate, require little maintenance if are properly manufactured and installed, have a rapid response, and can be made from silicon which is the second most abundant element in the earth's crust. Additionally, excepting the hybrid systems they contain no fluids or gases that can leak out, and in the mechanical sense have no moving parts to wear out $[1,2]$. The modular structure of manufactured solar PV cells allows their use in a wide range of applications, ranging from small scale remote applications (in microwatts range), residential use, to centralized energy farms, or high power plants with tens of megawatts power. Such a large-scale power handling capability also recommends PV cells in a wide range of decentralized or dispersed (on-site) installation, where the interconnection architecture of a high number of PV modules with significantly alternating electrical characteristics strongly influences the global performances of the entire plant. Therefore, in order to get benefit from application of PV systems, a huge amount of worldwide research activity is dedicated to gain further improvement in solar cells cost, reliability and energetic efficiency [3, 4, 5]. Among these efforts, this paper is focused to design and development a fast, accurate, and user-friendly PV simulator implemented in the LabView graphical programming language for modeling purposes, respectively to study and evaluate of PV cells energetic efficiency. The novel and versatile software toolkit has been developed upon the theoretical basis of the well known mathematical models used in international references for solar cell behaviors description, modeling, and simulation.

\section{PHOTOVOLTAIC CELL MODELS}

In principle, PV cells are devices which convert sunlight directly to electricity by generating a photovoltaic current within a thin layer of semiconductor structure embedding $p-n$ junctions. Theoretically, when exposed to sunlight photons are absorbed by the semiconductor atoms, freeing electrons from the negative layer which flows then to the positive layer generating an electric current which is directly proportional to solar irradiation. Understanding the physical configuration of the elements of the cell as well the electrical characteristics of each element it is possible to develop an accurate equivalent circuit for a PV cell $[5,6]$. The well known ideal equivalent circuit of a PV cell is shown in figure 1, and consists of a current source generator in parallel with a single diode.

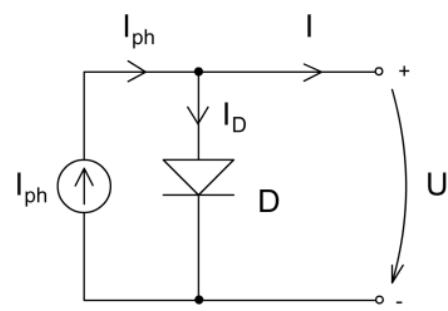

Fig. 1. The ideal PV cell model with single-diode

Writing the Kirchhoff theorems for this equivalent circuit results the following equation:

$$
I=I_{p h}-I_{0} \cdot\left\lfloor e^{\frac{q \cdot U_{D}}{n \cdot k \cdot T}}-1\right\rfloor=I_{p h}-I_{0} \cdot\left\lfloor e^{\frac{q \cdot U}{n \cdot k \cdot T}}-1\right\rfloor,
$$


where $I_{p h}$ is the photovoltaic current generated by the incidence of light, $I_{0} \approx 1 \cdot 10^{-11} \mathrm{~A} / \mathrm{cm}^{2}$ is the diode reverse bias saturation current, $q=1,6 \cdot 10^{-19} \mathrm{C}$ is the electron charge, $k=$ $1,38 \cdot 10^{-23} \mathrm{~J} / \mathrm{K}$ is the Bolzmann constant, $n$ the diode ideality factor ( $n=2$ for silicon diodes), and $T$ is the temperature of the pn junction.

More accuracy and complexity can be introduced to the previous ideal PV cell model by adding a parallel resistance, as shown in figure 2 [5].

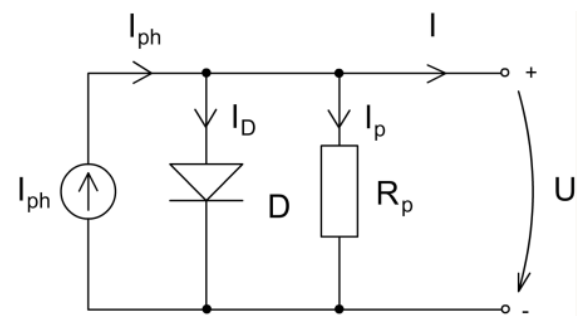

Fig. 2. The PV cell model with a single-diode and parallel resistance

In this case it is possible to express the following mathematical relation:

$$
I=I_{p h}-I_{D}-I_{P}=I_{p h}-I_{0} \cdot\left\lfloor e^{\frac{q \cdot U_{D}}{n \cdot k \cdot T}}-1\right\rfloor-\frac{U}{R_{p}} .
$$

The most common model used to predict energy production in PV cell modeling is the circuit configuration indicated in figure 3, where $R_{s}$ represents the equivalent series resistance and $R_{p}$ the parallel resistance. This model is a more practical one, which is widely used in studies and provides sufficient accuracy for most applications [5, 6].

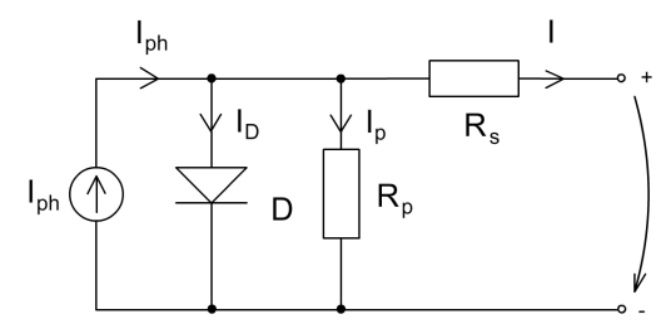

Fig. 3. The PV cell model with a single-diode, series and parallel resistance

Now the equation for the output current

$$
I=I_{p h}-I_{D}-I_{P}
$$

will be completed with the relation

and results that

$$
U_{D}=U_{s}+U
$$

$$
I_{p}=\frac{U_{d}}{R_{p}}=\frac{U+I \cdot R_{s}}{R_{p}}
$$

Substituting $I_{D}$ and $I_{p}$ in the equation (3), results:

$$
I=I_{p h}-I_{D}-I_{P}=I_{p h}-I_{0} \cdot\left\lfloor e^{\frac{q \cdot U_{D}}{n \cdot k \cdot T}}-1\right\rfloor-\frac{U+I \cdot R_{s}}{R_{p}}
$$

The equation (6) represents the I-V output characteristics of the solar PV cell.

\section{DETERMINATION OF MODEL PARAMETERS}

As it is well known, the performance characteristics of a PV module depend on its basic materials, manufacturing technology, and operating conditions. Usually all model parameters can be determined by examining the manufacturer's specification of PV products. However, an accurate knowledge of solar cell parameters from experimental data is of vital importance for the design of PV cells and for the estimates of their performance. The most important values of the PV cell $I-V$ characteristics are: the short-circuit current $I_{s c}$ (when the output voltage is zero and the generated current is at maximum), the open circuit voltage $V_{o c}$ (when the output current is zero and the voltage over the module is at maximum), and the maximum power point $P_{\max }$ (when the product of output current and voltage has its maximum) [5]. Typically, all these three points are provided in the manufacturer's product specification at standard test conditions. The main goal of every modeling effort is to reach an accurate estimation of these three points for different operation conditions. Thus, different PV cell models have been developed with the main purpose to describe their electrical behavior. The electrical equivalent circuits presented in the previous paragraph are a convenient and common way in a wide range of PV cell studies. The main parameters of interest in these equivalent circuits are the photo-current $I_{p h}$ the diode saturation current $I_{0}$, the parallel resistance $R_{p}$ that accounts for current leakage in the $p n$ junction, the series resistance $R_{s}$ which represents the structural resistances of a PV cell, and the diode ideality factor $n$ [5]. As is expressed in the equations (1), (2), and (6), the $I-V$ characteristics of a PV cell is both implicit and nonlinear, therefore it is difficult to solve in analytical way. The great majority of researchers dealing with the PV cells modeling problem uses numerical analysis methods to solve the nonlinear equation, or analytical methods with simplifications and approximations [4, 6]. Such solution methods returns sufficiently accurate results for the vast majority of research and experimental studies, and consistency between the data obtained via simulations and parameters given by the manufacturers.

A very similar concept with the above mentioned it is also expressed in this paper. There the main idea is to design and develop a fast and accurate PV cell simulator in the LabView graphical programming language, well suitable to modeling and compute the solar cells energetic efficiency. By using the PV cells equivalent electric circuit models presented in the previous paragraph, it is proposed to implement a versatile simulator with computed results in a good agreement with the datasheets provided by the manufacturer's ones. 


\section{DESIGN AND IMPLEMENTATION OF THE LABVIEW- BASED PV CELL SIMULATOR}

The LabView graphical programming language is a powerful, user-friendly, and versatile software toolkit developed by the National Instruments Corporation, allowing the convenient design and implementation of the most sophisticated user applications in electrical engineering. This toolkit it is also well suited to implement solar PV cell mathematical models and simulation tasks for a wide range of research purposes and studies. In figure 4 it is presented the LabView-based Front Panel of a fast and versatile PV cell simulator, designed in accordance with the theoretical remarks unfolded in the $2^{\text {nd }}$ paragraph. There are placed on the panel the following input magnitudes: the photo-current $I_{p h}$, the diode saturation current $I_{0}$, the parallel resistance $R_{p}$, the series resistance $R_{s}$, the required output voltage $U$, the diode ideality factor $n$, the PV cell operation temperature $T_{c}$, respectively the PV panel area in $\mathrm{m}^{2}$. The program computes the equivalent electric circuit models introduced and discussed in the solar PV cell models paragraph and returns accurate waveform diagrams regarding the cell output current evolution, output power generated, or PV cell energetic efficiency.

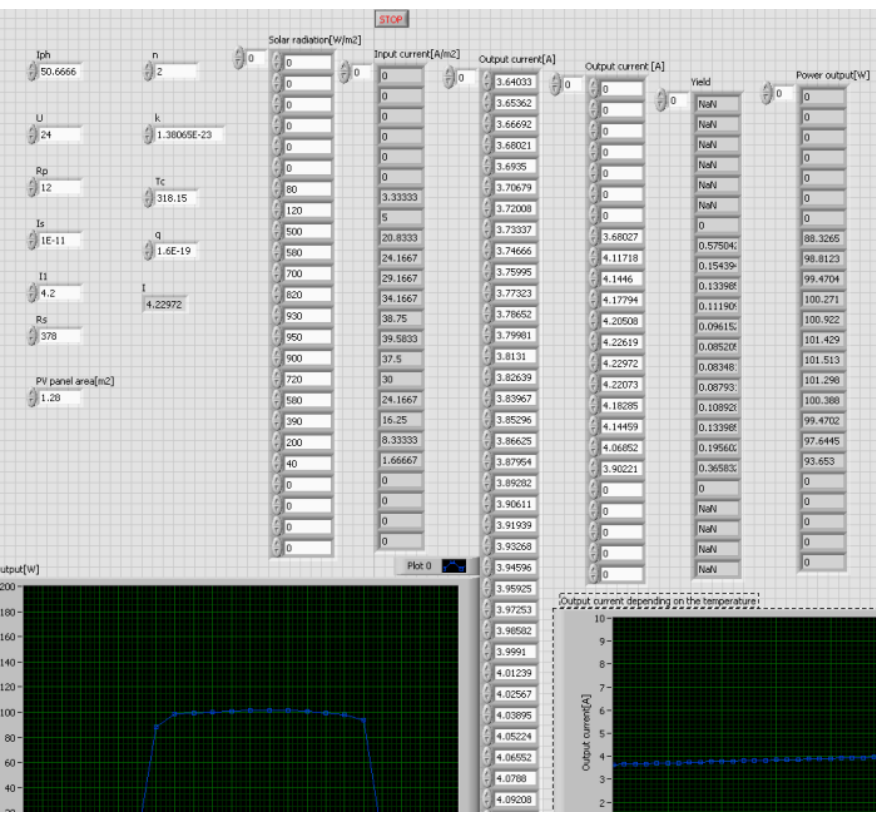

Fig. 4. The LabView Front Panel of the designed and implemented solar PV cell simulato

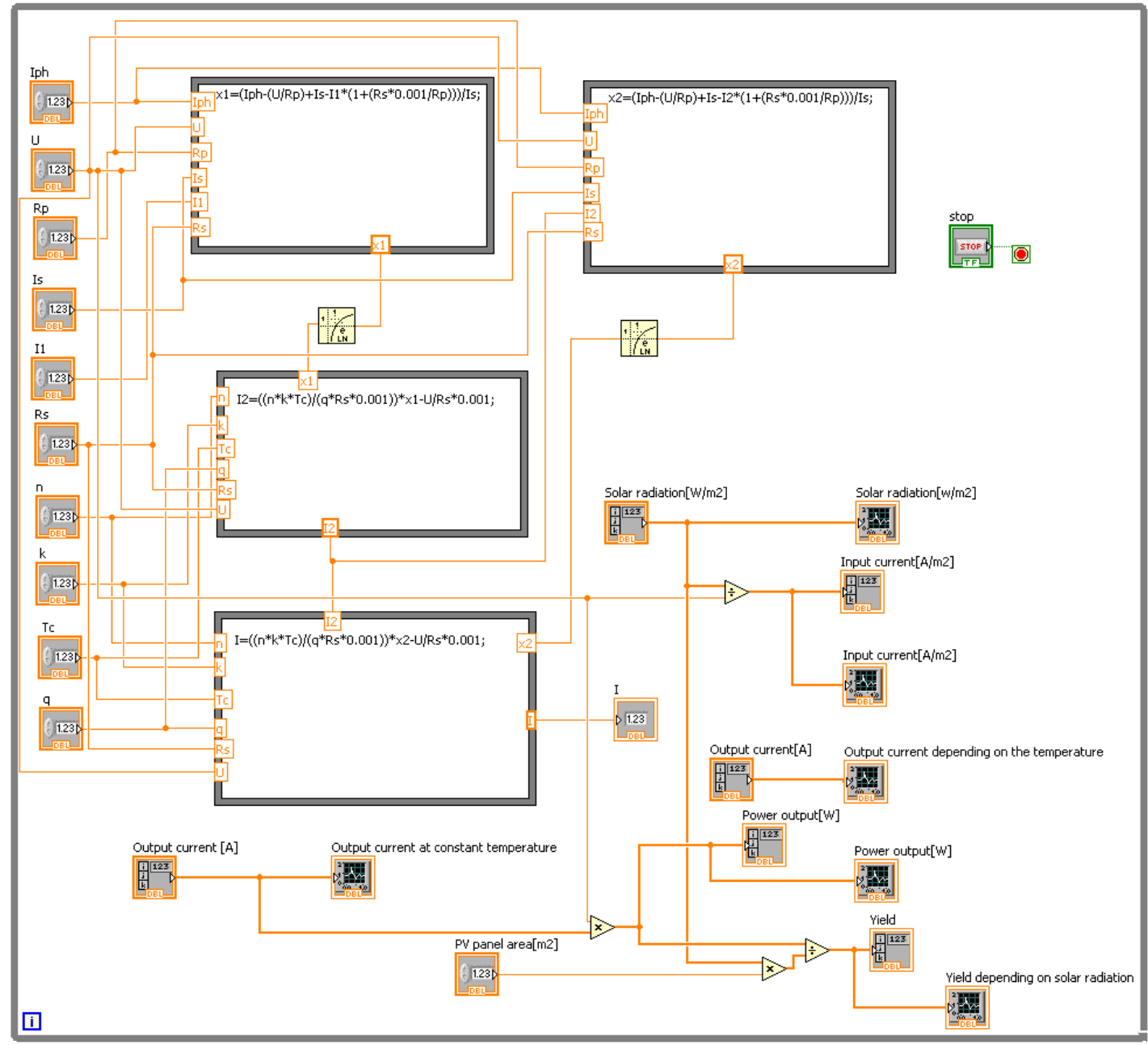


Fig. 5. The LabView Block Diagram of the implemented solar PV cell simulator

In figure 5 it is given the LabView Block Diagram of the developed program, with the adequate implemented equivalent mathematical models.

\section{EXPERIMENTAL VALIDATION OF THE PV CELL SIMULATOR PROGRAM}

For the simulations and experimental tests it is considered the monocrystalline Si PV panel LPS00236 cell shown below in figure 6, with its manufacturer's datasheet at standard test condition given in Table 1.

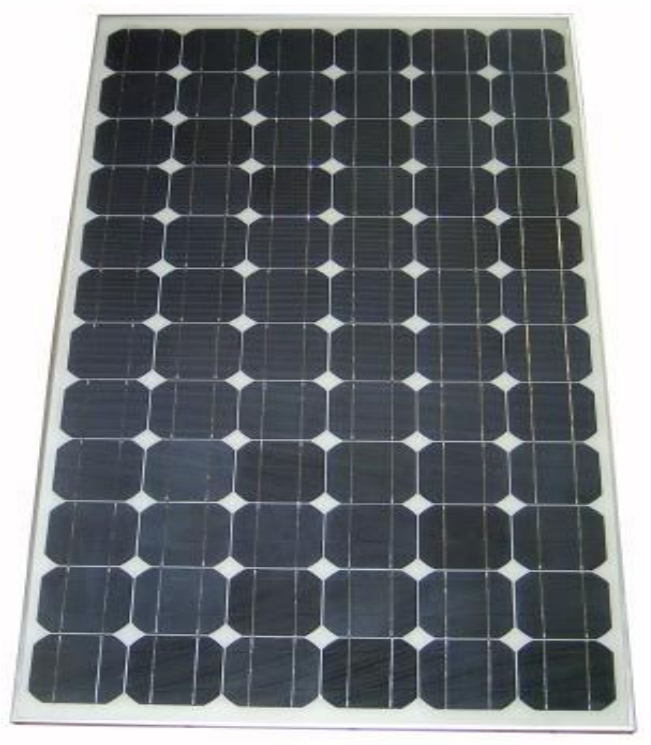

Fig. 6. The monocrystalline Si PV panel LPS00236

TABLE 1. MANUFACTURER'S DATASHEET OF THE PV PANEL LPS00236

\begin{tabular}{|l|c|}
\hline Characteristics & Specifications \\
\hline Cell type & mono-Si \\
\hline Typical peak power (W) & 145 \\
\hline Short-circuit current (A) & 4.85 \\
\hline Open-circuit voltage (V) & 42 \\
\hline Current at peak power (A) & 4.24 \\
\hline Voltage at peak power (V) & 34.2 \\
\hline Length (mm) & 1600 \\
\hline Width (mm) & 800 \\
\hline Panel area (m $\left.{ }^{2}\right)$ & 1.28 \\
\hline Nominal voltage (V) & $24 \mathrm{~V}$ \\
\hline
\end{tabular}

The first simulation result plotted in figure 7 refers to the ambient temperature influence on the PV cell output current if a variation in range of $0-45^{\circ}$ it is considered. The next simulations (figure 8 - figure 12) show the PV cell operation mode during a summer day. For example, in figure 8 it is indicated the 24 hour variation of the solar radiation which meets the PV cell in a day of august. Corresponding to this, in figure 9 it is plotted the generated photo-voltaic current $I_{p h}$ marked in the equivalent electric circuit of the PV cell. Figures
10,11 , and 12 show the output current variation, the energetic efficiency of the cell, respectively the generated output power.

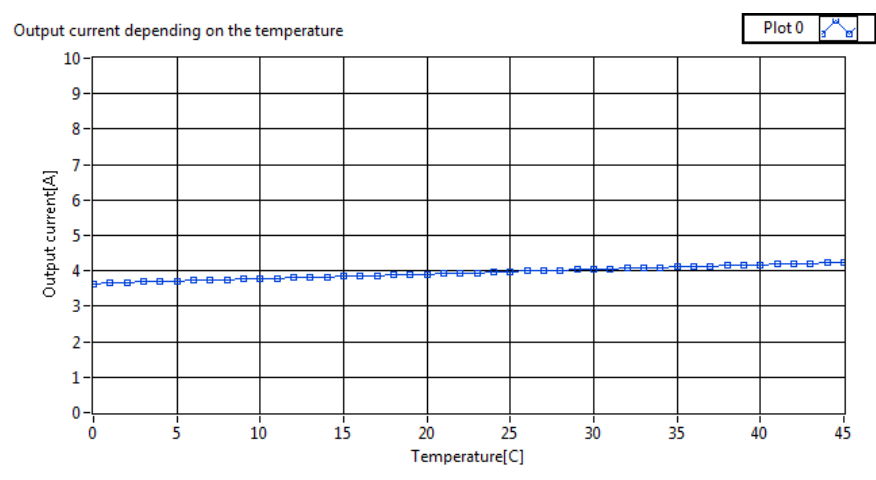

Fig. 7. The output current depending on the temperature variation

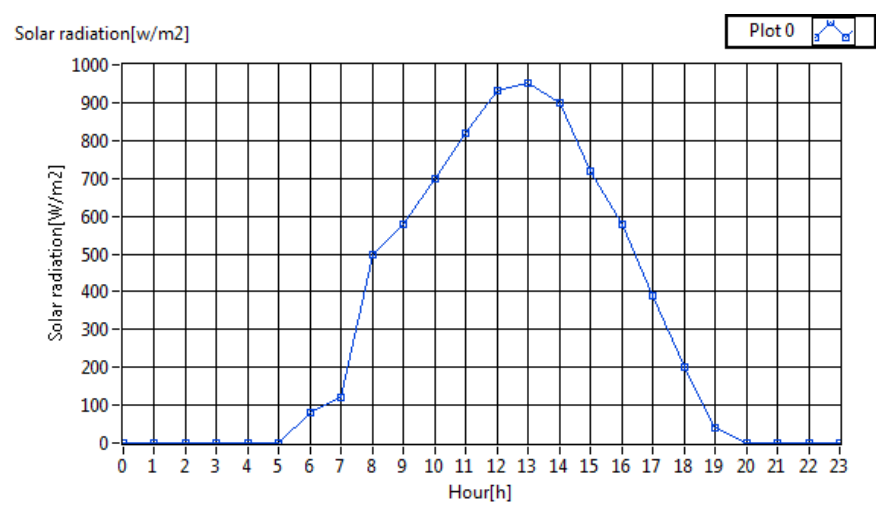

Fig. 8. The solar radiation variation during a day (august)

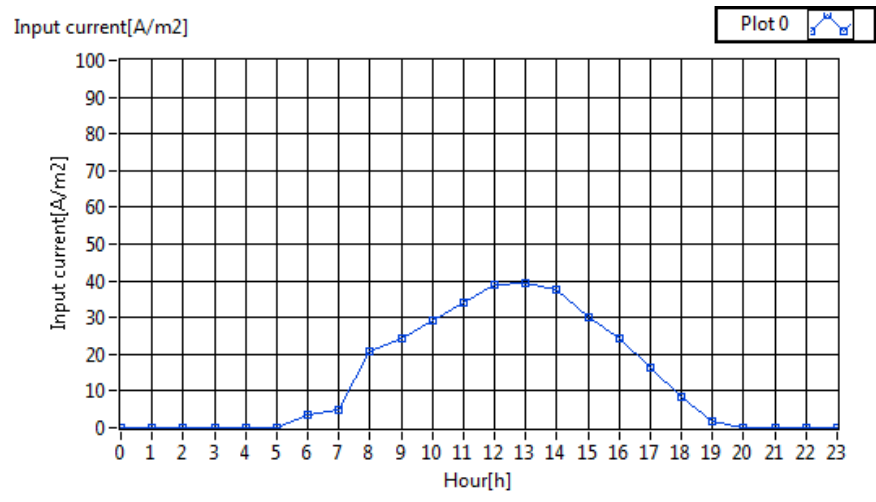

Fig. 9. The photo-voltaic current variation 


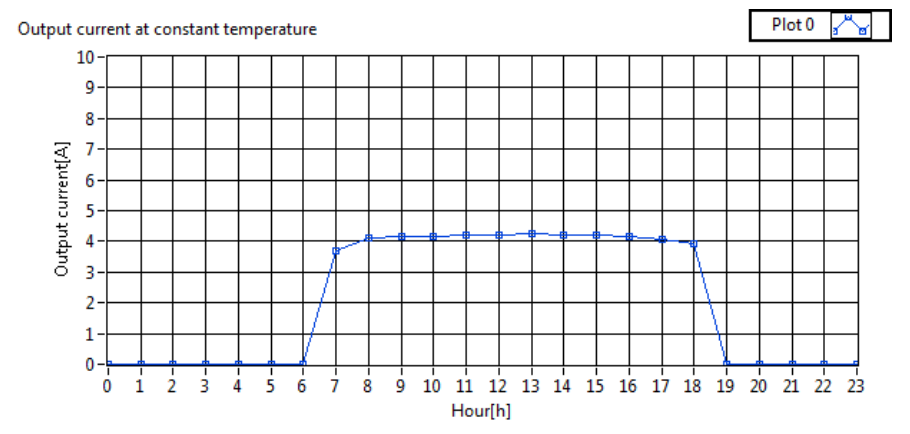

Fig. 10. The output current variation

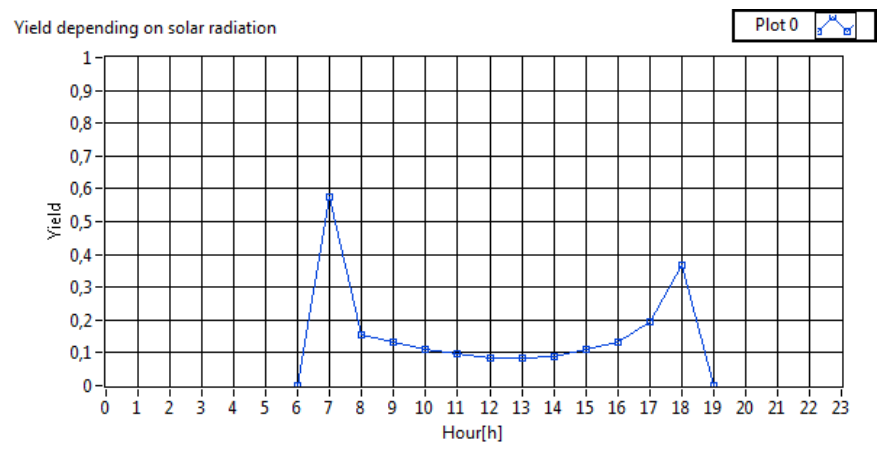

Fig. 11. The energetic efficiency of the PV cell

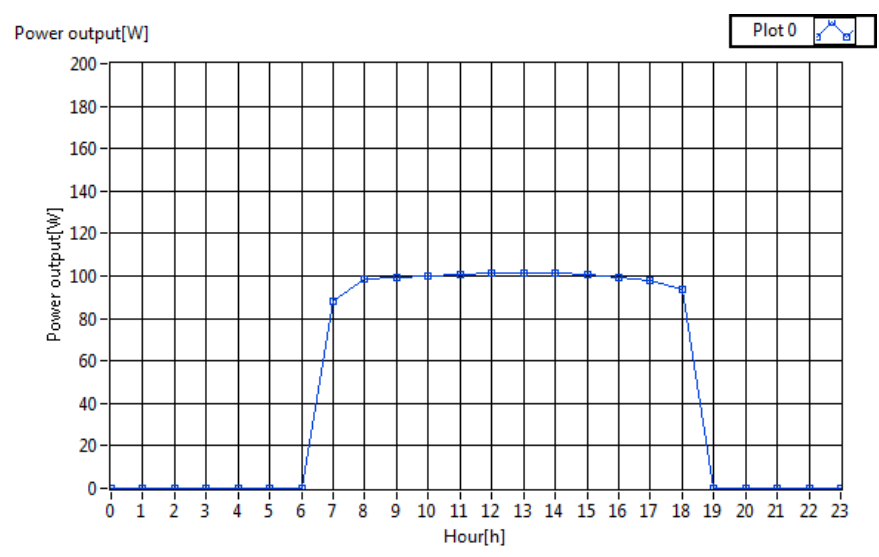

Fig. 12. The output power of the PV cell

It is interesting to mention here that the PV cell operates at maximal efficiency in the beginning of the day (hour 7 at morning) and the end of the day around 18 o'clock. The next simulation result set (figure 13 - figure 17) plots the same magnitudes of the solar PV cell in October, in the same year. There the difference consist on the fact that instead of the maximal solar radiation amplitudes of a summer day fitted around into the time interval of 10 hour - 16 hour, in October these maximal values shifts in the time range of the 13 hour 17 hour. In other words in an autumn day the captured solar energy (sun light intensity ) reaches its maximal values in the afternoon hours of the day.

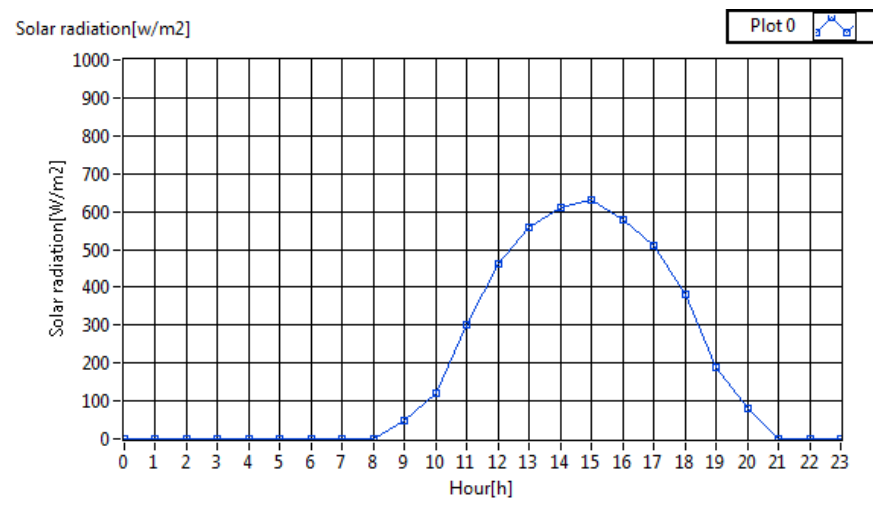

Fig. 13. The solar radiation variation during a day (october)

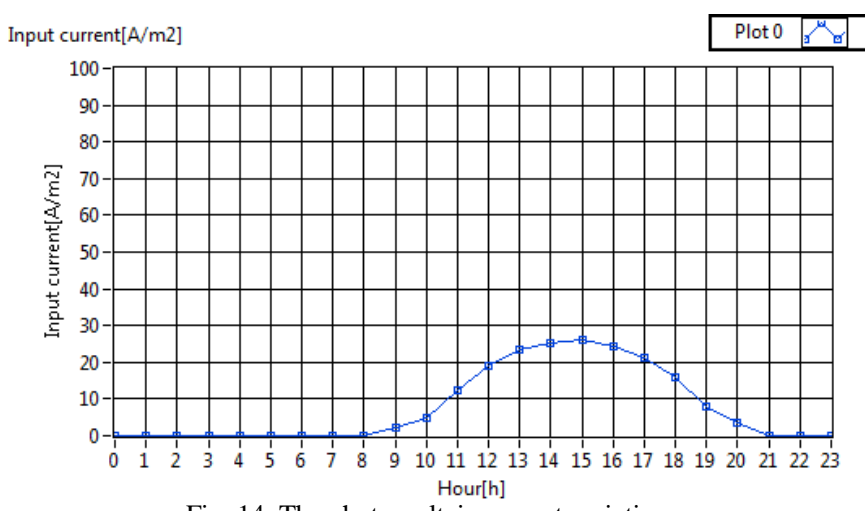

Fig. 14. The photo-voltaic current variation

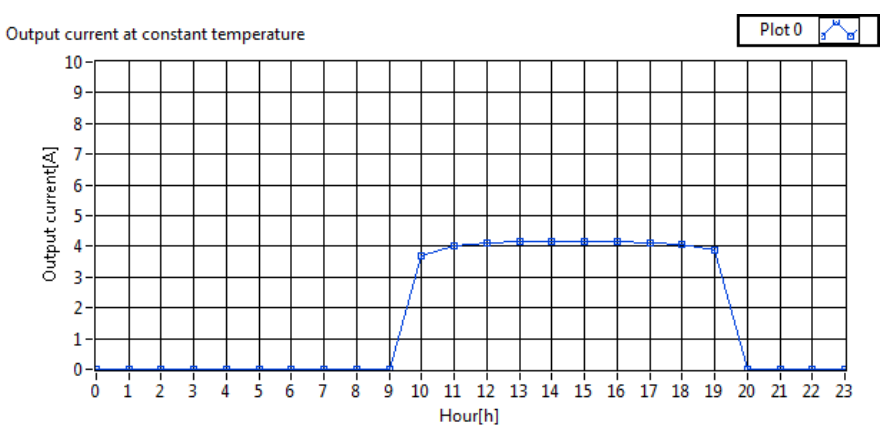

Fig. 15. The output current variation

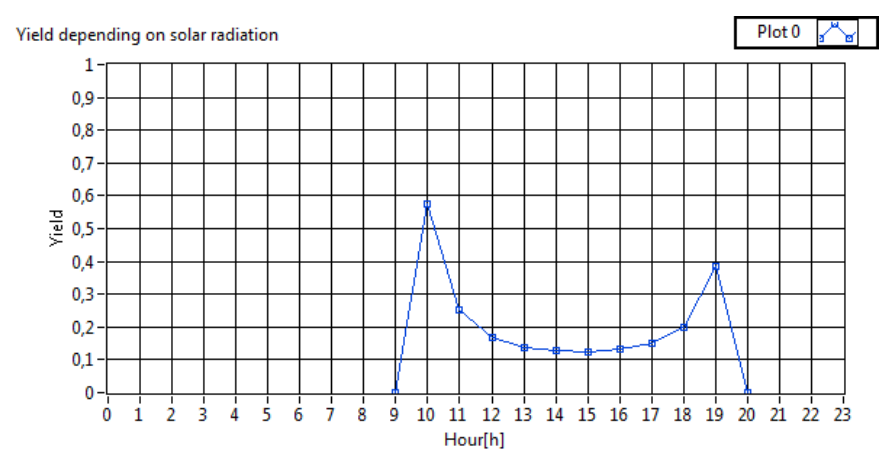

Fig. 16. The energetic efficiency of the PV cell 


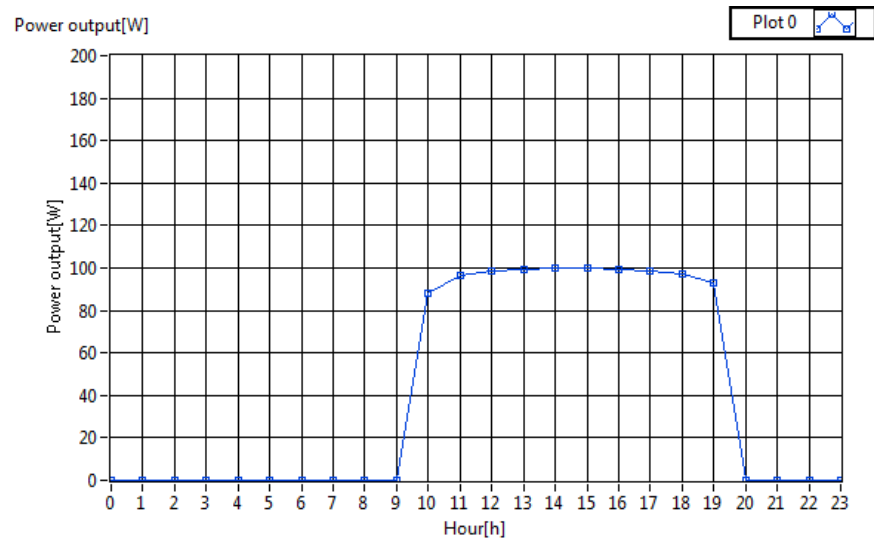

Fig. 17. The output power of the PV cell

It is not without importance to mention here that the simulated results are in a good agreement with the manufacturer's given datasheets ones. This means that for input values corresponding to standard test conditions the simulator generates very similar values for the main parameters given in the manufacturer's datasheet provided in Table 1.

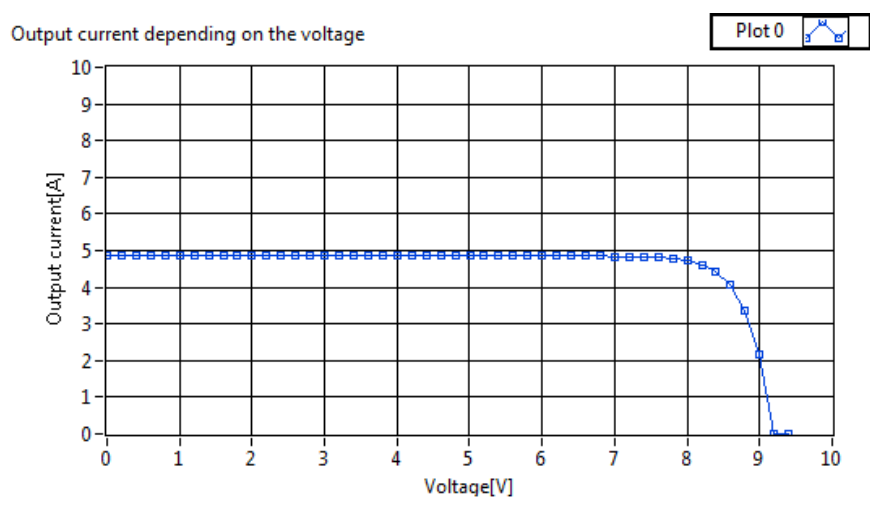

Fig. 18. The $I-V$ characteristics of the simulated PV cell

The last simulation result refers to the well known $I-V$ characteristics of the considered PV cell. This diagram points out the short-circuit current $I_{s c}$, the open circuit voltage $V_{o c}$ and the maximum power point $P_{\max }$, values that also are in good agreement with catalogue data provided by the manufacturer.

\section{CONCLUSION}

The paper deals with validation of a fast and accurate solar PV cell simulator designed and implemented in the LabView graphical programming software environment. This simulation toolkit has been specially developed for energetic efficiency estimation of PV cells. The simulation models used have been validated via simulations and the obtained results are in concordance with the catalogue specifications given by the manufacturers of PV cells. This means that the implemented program can serve as a useful toolkit for engineers and researchers who require precise simulation datasheets in various operation conditions of any photovoltaic modules.

\section{REFERENCES}

[1] P. Hersch, "Basic photovoltaic principles and methods", United States Department for Energy, SERI/SP-290-1448, USA, Feb. 1982.

[2] R.W. Miles, K.M. Hynes, I. Forbes, "Photovoltaic solar cells: An overview of state-of-the-art cell development and environmental issues", Elsevier, $\quad$ DOI: $\quad 10.1016 /$ j.pcrysgrow.2005.10.002, www.elsevier,com/locate/pcrysgrow

[3] sT. Salmi, M. Bousgueda, A. Gastli, and A. Masmoud, "Matlab/Simulink based modelling of solar photovoltaic cell", International Journal of Renewable Energy Research, vol 2, no 2, 2012.

[4] U. Stutenbaumer, B. Mesfin, "Equivalent model of monocrystaline, polycrystaline, and amorphous silicon solar cells", Renewable Energy 18, pp. 5011-512, 1999.

[5] D. Boukoungou, Z. Koalaga, D. Njano, “ Modelling and simulation of photovoltaic module considering single-diode equivalent model in Matlab", International Journal of Emerging Technology and Advanced Engineering, vol 3, issue 3, 2013, ISSN 2250-2459.

[6] J. Kumari, Ch. Babu, "Mathematical modelling and simulation of photovoltaic cell using matlab-Simulink environment", International Journal of Electrical and Computer Engineering, vol 2, no 1, Feb.2012, pp. 26-34, ISSN: 2088-8708. 